\title{
Effects of miR-103a-3p on the autophagy and apoptosis of cardiomyocytes by regulating Atg5
}

\author{
CHENJUN ZHANG, JIDE LU, HAIRONG WANG, YUAN QI, YING KAN and ZHIRU GE
}

Department of Cardiology, Shanghai Pudong New Area Gongli Hospital, Shanghai 200135, P.R. China

Received November 9, 2018; Accepted February 11, 2019

DOI: $10.3892 / \mathrm{ijmm} .2019 .4128$

\begin{abstract}
Autophagy and apoptosis are associated with cardiovascular diseases. Emerging evidence shows that microRNAs (miRs) are critical in the development of pathological processes underlying cardiovascular diseases by regulating the induction of apoptosis and autophagy. The present study aimed to investigate the role of miR-103a-3p in cardiomyocyte injury through autophagy and apoptosis. H9c2 cells were cultured under hypoxia and reoxygenation $(\mathrm{H} / \mathrm{R})$ conditions and were used to mimic cells under ischemia. The transfection of cells with miR-103a-3p (mimics and inhibitors) was performed to examine its function in cardiomyocytes. The expression levels of miR-103a-3p were evaluated by reverse transcription-quantitative polymerase chain reaction analysis. Cell viability was determined using an MTT assay, and the lactate dehydrogenase assay ( $\mathrm{LDH}$ ) was used to investigate cell injury. The expression levels of B-cell lymphoma 2 (Bcl-2), Bcl-2-associated X protein, Beclin-1, autophagy-related 5 (Atg5), cleaved caspase-3 and cleaved caspase-9 were detected using western blotting. Immunofluorescence assays were performed to detect the expression of LC3 as a marker of autophagy. The target gene of miR-103a-3p was identified using dual-luciferase reporter assays. The results revealed that the expression levels of miR-103a-3p were significantly downregulated in cardiomyocytes under $\mathrm{H} / \mathrm{R}$ conditions. Injury of the cardiomyocytes was evaluated under $\mathrm{H} / \mathrm{R}$ conditions. Following transfection of the cells with miR-103a-3p inhibitors, cell injury was increased, as determined by LDH and MTT assays. The expression levels of apoptotic proteins were consistent with the results obtained in the LDH and cell viability assays. The induction of autophagy was increased in cells under $H / R$ conditions and cells with miR-103a-3p inhibitor transfection, whereas the induction of autophagy was decreased in cells transfected with miR-103a-3p mimics. In addition, the data indicated that miR-103a-3p directly targeted
\end{abstract}

Correspondence to: Dr Zhiru Ge, Department of Cardiology, Shanghai Pudong New Area Gongli Hospital, 219 Miaopu Road, Pudong New Area, Shanghai 200135, P.R. China

E-mail: gezhiru_pdxq@outlook.com

Key words: microRNA-103a-3p, autophagy, apoptosis, cardiomyocytes, autophagy-related gene 5
Atg5, which regulated the induction of autophagy and apoptosis. Taken together, these findings indicate that, following the inhibition of miR-103a-3p, Atg5 promotes autophagy and apoptosis in cardiomyocytes by directly targeting Atg5. Therefore, miR-103a-3p can be considered a potential therapeutic target for myocardial ischemia.

\section{Introduction}

The incidence and mortality rates of coronary heart disease are increasing annually. Acute myocardial infarction (AMI) is a disease with a high mortality rate, which can cause significant damage to myocardial tissues and lead to disability or mortality. AMI mainly refers to regional myocardial ischemic necrosis caused by acute coronary artery occlusion and blood flow rupture. Therefore, early opening of the infarct vessel and reperfusion of the ischemic myocardium are the most effective methods to repair extensive myocardial damage (1). However, reperfusion can lead to myocardial cell injury, which is termed reperfusion injury. Reperfusion injury can cause more extensive cell loss and further expand the area of the ischemic myocardium, affecting patient survival rate (2). A previous study showed that the final area of myocardial necrotic tissue, estimated to cover $\sim 50 \%$ of the total tissue region, may be associated with reperfusion injury (3). The reduction of reperfusion injury can significantly reduce the extent of the final necrotic area of the myocardial tissue, and thus improve long-term cardiac function in patients with AMI. Therefore, the mechanism of reperfusion injury requires extensive investigation for the development of novel therapeutic approaches for AMI.

Autophagy is the process by which cells use lysosomes to degrade their damaged organelles and macromolecules. It has an important role in cell growth, development and the maintenance of cell homeostasis (4). Autophagy is implicated in cellular housekeeping duties and the maintenance of intracellular homeostasis through the removal of damaged proteins and organelles, however, the chronic upregulation of autophagy may result in an imbalance of homeostatic conditions under pathophysiological conditions (5). In cardiomyocytes in nutrient deprivation conditions, ischemic injury induces autophagy by activating the AMPK signaling pathways (6). However, if the ischemic event is more severe, for example, in acute myocardial infarction and ischemia/reperfusion (I/R) injury, the increase in autophagic flux may lead to cell death, and exacerbate cardiac diseases, including heart failure (7-9). 
MicroRNAs (miRNAs) are small, endogenous, non-coding RNAs with a length of $\sim 22$ nucleotides. These molecules are important in the post-transcriptional regulation of various genes. In the human genome, $\sim 1,000$ miRNA families have been identified, with each family including hundreds of target miRNAs $(10,11)$. The total number of miRNA molecules in a cell regulates the expression of at least $30 \%$ of the genes. Therefore, miRNAs are involved in almost all cell function activities, including cell growth, differentiation and disease progression, acting as major contributors in the regulation of cellular activity (12-14). Previous studies have suggested that miRNAs are important in the regulation of cellular stress, including hypoxia, nutritional deprivation and DNA damage (15-17). Previous studies have indicated that numerous miRNAs, including miRNA (miR)-214 and miR-21, are associated with myocardial protection $(18,19)$. miR-214 and miR-21 exert a cardioprotective effects during cardiomyocyte ischemia. miR-103a-3p has been shown to be overexpressed and to promote malignant transformation in several types of cancer (20-22). Circular RNA expression profiles have revealed the regulatory role of the circTCF25-miR-103a-3p pathway in bladder carcinoma (21). However, there have been no investigations of the interaction between miR-103a-3p and cardiomyocytes.

Autophagy is regulated by the autophagy-related gene (Atg), which is involved in the formation of autophagosomes (23). Following mature autophagosome formation, Atg5-Atg12 conjugates are localized to phagophores and separated (24). The conjugation of Atg5-Atg12 is activated by the class III PI-3-kinase (Vps34) (25). In addition, the activation of Vps34 is positively regulated by Beclin-1 (26). Under normal conditions, the $\mathrm{BH}$ domain of the Beclin-1 protein binds to $\mathrm{B}$-cell lymphoma 2 (Bcl-2) and/or Bcl-2-like protein (Bcl-xL) to inhibit autophagy. However, under stress conditions, including a lack of growth factor supply or starvation, the induction of autophagy is activated when the $\mathrm{Bcl}-2$ or $\mathrm{Bcl}-\mathrm{xL}$ proteins are separated from Beclin-1 (27). Beclin-1 is required for Atg5-dependent or -independent autophagy (28). Microtubule associated protein light chain 3 (MAP-LC3/Atg8/LC3) is conjugated with phosphatidylethanolamine (PE) involved in the second modification. Cytosolic LC3 is cleaved to form LC3-I, LC3-I is conjugated to PE to form LC3-II, and LC3II specifically targets phagophores associated with Atg5-Atg12. At present, LC3 is the only protein known to be associated with autophagosomes specifically. Therefore, the levels of LC3II can be used to assess autophagosome number (29).

To the best of our knowledge, the present study is the first to demonstrated the abnormal expression of miR-103a-3p in a myocardial ischemia/reperfusion in vitro model. To improve the understanding of the role of miR-103a-3p in the induction of autophagy and apoptosis in cardiomyocytes, the present study investigated the effects of miR-103a-3p on the autophagy and apoptosis of H9c2 cells under hypoxia/reoxygenation $(\mathrm{H} / \mathrm{R})$ conditions. The involvement of autophagy-related gene expression in this process was also examined.

\section{Materials and methods}

Cell culture and treatment. $\mathrm{H} 9 \mathrm{c} 2$ cardiomyocytes were obtained from the Cell Line Bank of the Chinese Academy of Sciences (Shanghai, China) and cultured in high glucose (4.5 g/l) Dulbecco's modified Eagle's medium (DMEM; Gibco; Thermo Fisher Scientific, Inc., Waltham, MA, USA) supplemented with $10 \%$ fetal bovine serum (FBS; Gibco; Thermo Fisher Scientific, Inc.), at $37^{\circ} \mathrm{C}$ and $5 \% \mathrm{CO}_{2}$. To mimic ischemia, the cells were cultured in low glucose $(1.0 \mathrm{~g} / \mathrm{l})$ DMEM (Gibco; Thermo Fisher Scientific, Inc.), placed in a hypoxic incubation chamber with $90 \% \mathrm{~N}_{2}$ and $5 \% \mathrm{CO}_{2}$ for $24 \mathrm{~h}$. Subsequently, the cells were reoxygenated by incubation with high glucose DMEM supplemented with $10 \%$ FBS at $37^{\circ} \mathrm{C}$ in the presence of $5 \% \mathrm{CO}_{2}$.

Transfection. The H9c2 cells were plated in 6-well plates $\left(1 \times 10^{5}\right.$ per well) and incubated at $37^{\circ} \mathrm{C}$ for $24 \mathrm{~h}$. The cells were transiently transfected with a final $20 \mathrm{nM}$ dose of miR-103a-3p mimics (cat. no. miR10000101-1-5), miR-control (miR-con; cat. no. miR1N0000001-1-5), miR-103a-3p inhibitor (cat. no. miR20000101-1-5), inhibitor-con (cat. no. miR2N0000001-1-5), Atg5 small interfering (si)RNA (cat. no. siB160225095638-1-5) or siRNA-con (cat. no. siN0000002-1-5; all from Guangzhou RiboBio Co., Ltd., Guangzhou, China) using Lipofectamine 2000 (Invitrogen; Thermo Fisher Scientific, Inc.) according to the manufacturer's protocol. Subsequent analysis of the different cell groups was performed following incubation for $48 \mathrm{~h}$.

Reverse transcription-quantitative polymerase chain reaction $(R T-q P C R)$ analysis. The H9c2 cells were plated in 6-well plates $\left(1 \times 10^{5}\right.$ per well). Following transfection, the cells were cultured for $48 \mathrm{~h}$ and total RNA was extracted using TRIzol reagent (Invitrogen; Thermo Fisher Scientific, Inc.). The concentration and purity of the RNA were measured using the NanoDrop system. Complementary DNAs (cDNAs) were synthesized using RevertAid first strand cDNA (Fermentas; Thermo Fisher Scientific, Inc.) or a Taqman microRNA reverse transcription kit (Applied Biosystems; Thermo Fisher Scientific, Inc.) according to the manufacturer's protocol. The cDNA samples were amplified using Power SYBR ${ }^{\circledR}$-Green PCR Master mix or a TaqMan microRNA assay (Applied Biosystems; Thermo Fisher Scientific, Inc.), according to the manufacture's protocol. In brief, the PCR amplification program was the following: $95^{\circ} \mathrm{C}$ for $20 \mathrm{sec}$, followed by 40 cycles of $95^{\circ} \mathrm{C}$ for $1 \mathrm{sec}$ and $60^{\circ} \mathrm{C}$ for $20 \mathrm{sec}$. In addition, $\mathrm{ddH}_{2} \mathrm{O}$ as the non-template control was analyzed for every plate. The primers used were as follows: miR-103a-3p forward, 5'-ACACTCCAGCTGGGAGCAGCATTGTAC AGGG-3' and reverse, 5'-TGGTGTCGTGGAGTCG-3'; U6 forward, 5'-CTCGCTTCGGCAGCACA-3' and reverse, 5'-AAC GCTTCACGAATTTGCGT-3'; Atg5 forward 5'-TATCAGAGC ATGTCACCCTT-3' and reverse, 5'-TTCCTGTCTGGCTTG CAGCA; and GAPDH forward, 5'-GGCACAGTCAAGGCT GAGAATG-3' and reverse, 5'-ATGGTGGTGAAGACGCCA GTA-3'. U6 was used for normalization the expression levels of miR-103a-3p. GAPDH was used for normalization the expression levels of Atg5. Relative expression was quantified by the $2^{-\Delta \Delta C q}$ method (30).

MTT assay. The H9c2 cells were plated in 96-well plates $\left(1 \times 10^{4}\right.$ per well). Following transfection, the cells were cultured for $48 \mathrm{~h}$. A total of $20 \mu 1 \mathrm{MTT}$ reagent $(5 \mathrm{mg} / \mathrm{ml}$; Sigma-Aldrich; Merck KGaA, Darmstadt, Germany) was 
added to each well, and the cells were incubated at $37^{\circ} \mathrm{C}$ for $4 \mathrm{~h}$. Subsequently, $150 \mu \mathrm{l}$ of dimethyl sulfoxide (DMSO; Sigma-Aldrich; Merck KGaA) was added, and the absorbance of each well was measured on a microplate reader at $490 \mathrm{~nm}$.

Lactate dehydrogenase ( $L D H)$ assay. The H9c2 cells were plated in 24 -well plates $\left(1 \times 10^{5}\right.$ per well) and were separately transfected with miR-103a-3p mimics, miR-con, miR-103a-3p inhibitor, inhibitor-con, Atg5 siRNA or siRNA-Con. The LDH leakage assay was performed to determine cell injury using the LDH cytotoxicity assay kit (Beyotime Institute of Biotechnology, Haimen, China) according to the manufacturer's protocol. The absorbance was measured at $490 \mathrm{~nm}$.

Western blot analysis. The H9c2 cells were plated in 6-well plates $\left(1 \times 10^{5}\right.$ per well). Following transfection for $48 \mathrm{~h}$, total protein was lysed using the RIPA lysis buffer(Beyotime Institute of Biotechnology). The concentration and purity of the protein were measured using the NanoDrop system. Protein samples of $40 \mu \mathrm{g}$ per lane were separated on SDS-PAGE gels $(10 \%)$ and transferred onto polyvinylidene difluoride membranes (EMD Millipore, Bedford, MA, USA). The membranes were blocked for $2 \mathrm{~h}$ in $5 \%$ skimmed milk at room temperature and subsequently incubated with primary antibodies (Beclin-1, cat. no. sc-48341, 1:1,000; Atg5, cat. no. sc-133158, 1:1,000; Bcl-2, cat. no. sc-7382, 1:1,000; Bax, cat. no. sc-7480, 1:1,000; cleaved caspase-3, cat. no. sc-65496, 1:1,000; cleaved caspase-9, cat. no. sc-56076, 1:1,000; GAPDH, cat.no. sc-47724, 1:1,000; Santa Cruz Biotechnology, Inc., Dallas, TX, USA) overnight at $4^{\circ} \mathrm{C}$. The membranes were then washed with TBST three times, incubated with horseradish peroxidase-labelled secondary antibodies (cat. no. 7074, 1:10,000; Cell Signaling Technology, Inc., Danvers, MA, USA) for $2 \mathrm{~h}$ at room temperature, and further washed with TBST three times. Subsequently, the blots were detected using the enhanced chemiluminescence kit and analyzed using ImageJ k1.45 software (National Institutes of Health, Bethesda, MD, USA).

Immunofluorescence. The cells on coverslips were fixed in $4 \%$ paraformaldehyde for $20 \mathrm{~min}$ and permeabilized with $0.2 \%$ Triton X-100 in phosphate buffered saline (PBS) for $10 \mathrm{~min}$. The samples were blocked with PBS containing $2 \%$ bovine serum albumin (Sigma-Aldrich; Merck KGaA) for $1 \mathrm{~h}$ at room temperature and further incubated with primary antibodies (LC3, cat. no. 2775, 1:200; Cell Signaling Technology, Inc.) overnight at $4^{\circ} \mathrm{C}$. The following day, the samples were incubated with secondary antibodies (cat. no. 1647, 1:200; Invitrogen; Thermo Fisher Scientific, Inc.) for $2 \mathrm{~h}$ at room temperature in the dark. Finally, the cells were stained with 4',6-diamidino-2-phenylindole (Sigma-Aldrich; Merck KGaA) for $5 \mathrm{~min}$. The coverslips were washed with PBS following each step. Images were captured using an Olympus IX50 inverted fluorescence microscope (Olympus Corporation, Tokyo, Japan).

Luciferase reporter assay. The $\mathrm{H} 9 \mathrm{c} 2$ cells were plated in 24 -well plates $\left(1 \times 10^{5}\right.$ per well) and then co-transfected with a pmir-GLO dual-luciferase miRNA target expression vector (Promega Corporation, Madison, WI, USA), containing a wild-type or mutant Atg5 3'untranslated region (3'UTR), and
miR-103-3p mimics or miR-con using Lipofectamine 2000 (Invitrogen; Thermo Fisher Scientific, Inc.). Following $48 \mathrm{~h}$ of incubation, the luciferase activity was measured using a dual luciferase reporter gene assay kit (Beyotime Institute of Biotechnology) according to the manufacturer's protocol.

Statistical analysis. All data are presented as the mean \pm standard deviation. Significant differences were determined using Student's t-test or one-way analysis of variance followed by Tukey's test. Data were analyzed using SPSS version 20.0 (IBM Corp., Armonk., NY, USA). P<0.05 was considered to indicate a statistically significant difference.

\section{Results}

Expression levels of miR-103a-3p are decreased significantly in hypoxia-induced H9c2 cardiomyocytes. To examine the functional role of miR-103a-3p in cardiomyocytes, its levels were examined in the following groups: H9c2 cells or negative control (NC) group (H9c2 cells only), H9c2 H/R group (H9c2 cells under H/R conditions), H9c2 miR-103a-3p mimics group (H9c2 cells transfected with miR-103a-3p-mimics) and/or miR-103a-3p inhibitor group (H9c2 cells transfected with miR-103a-3p inhibitor). The expression levels of miR-103a-3p were significantly lower in the H9c2 cells under $\mathrm{H} / \mathrm{R}$ conditions compared with those noted in the NC group, as shown in Fig. 1A. To further investigate the role of miR-103a-3p, the H9c2 cells were transfected with miR-103a-3p mimics and miR-103a-3p inhibitors. The miR-103a-3p mimics group exhibited a significantly higher level of miR-103a-3p compared with that in the mimic-con group, whereas the miR-103a-3p inhibitor exhibited a significantly lower level compared with that in the inhibitor-con group, as shown in Fig. 1A. No significant differences were observed between the mimic-con or inhibitor-con and NC groups. These results indicated that the transfection was efficient.

Cell viability is affected by the expression of $m i R-103 a-3 p$. To examine the effect of miR-103a-3p, the H9c2 miR-103a-3p mimics H/R group (H9c2 miR-103a-3p mimics group cells treated under $\mathrm{H} / \mathrm{R}$ conditions) was used for cell viability experiments. The viability of $\mathrm{H} 9 \mathrm{c} 2$ cells under $\mathrm{H} / \mathrm{R}$ conditions and of H9c2 cells transfected with miR-103a-3p inhibitor were significantly decreased compared with that of the NC cells, whereas no significant difference was observed between the inhibitor-con and NC groups (Fig. 1B). However, the cell viability of the miR-103a-3p mimics H/R group was significantly higher than that of the H/R group, whereas no significant difference was noted between the $\mathrm{NC}$ and mimic-con groups. These results revealed that the viability of $\mathrm{H} 9 \mathrm{c} 2$ cells was increased following an increase in the expression of miR-103a-3p.

Expression of miR-103-3p is associated with the induction of H9c2 cardiomyocyte apoptosis. To detect the induction of apoptosis in H9c2 cardiomyocytes, the LDH cytotoxicity assay kit was used. LDH leakage in the H/R and miR-103a-3p inhibitor groups was increased compared with leakage in the $\mathrm{NC}$ and the inhibitor-con groups, whereas no significant difference was noted between the inhibitor-con and NC groups. In 

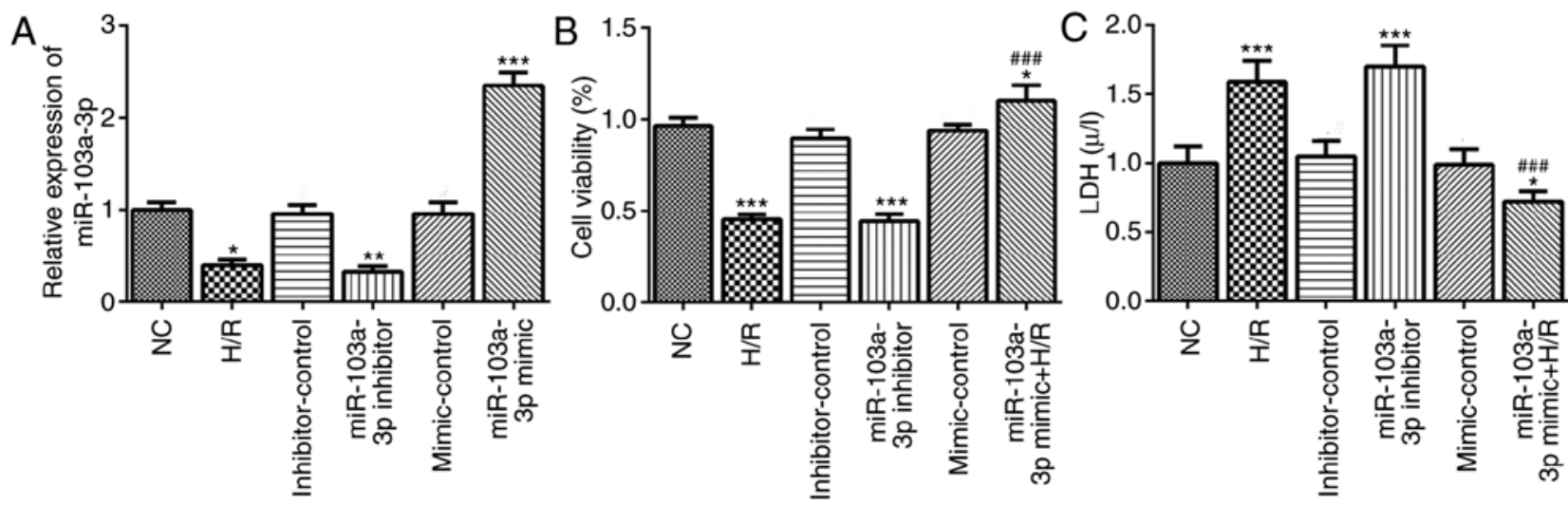

Figure 1. Effects of miR-103a-3p on H9c2 cell viability. (A) Transfection efficiency of miR-103a-3p inhibitor and miR-103a-3p mimics detected via reverse transcription-quantitative polymerase chain reaction analysis. (B) MTT assays for the detection of cell viability. (C) Cell injury was determined via the leakage of LDH. NC, untreated H9c2 cells; H/R, H9c2 cells under H/R; mimic-Control, H9c2 cells transfected with miRNA mimic control; miR-103a-3p mimics, H9c2 cells transfected with miR-103a-3p mimic; miR-103a-3p mimics + H/R, H9c2 cells transfected with miR-103a-3p mimic and then H/R; miR-103a-3p inhibitor, H9c2 cells transfected with miRNA inhibitor; inhibitor-Control, H9c2 cells transfected with miRNA inhibitor control. All data are expressed as the mean \pm standard deviation. ${ }^{*} \mathrm{P}<0.05,{ }^{* *} \mathrm{P}<0.01$ and ${ }^{* * *} \mathrm{P}<0.001$, vs. NC; ${ }^{\# \# \#} \mathrm{P}<0.001$, vs. H/R. miR, microRNA; NC, negative control; H/R, hypoxia/reoxygenation; LDH, lactate dehydrogenase.
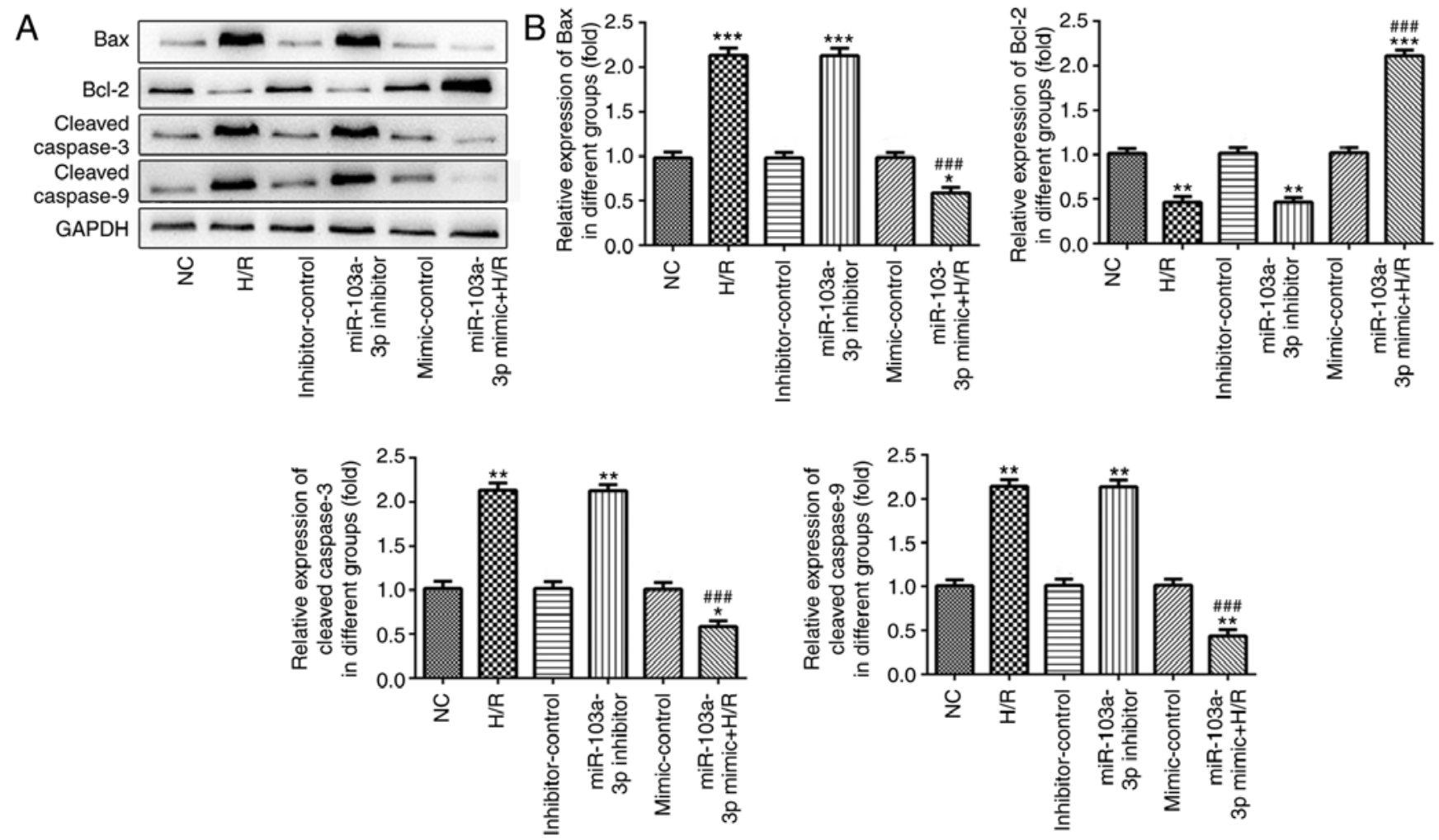

Figure 2. Expression of apoptotic proteins and autophagy-related proteins in H9c2 cells under H/R conditions, in H9c2 cells transfected with miR-103a-3p mimics and/or miR-103a-3p inhibitors. (A) Protein expression levels of Bax, Bcl-2, cleaved caspase-3 and cleaved caspase-9 were determined by western blotting. (B) Quantitative evaluation of the protein expression levels. NC, untreated H9c2 cells; H/R, H9c2 cells under H/R; mimic-Control, H9c2 cells transfected with miRNA mimic control; miR-103a-3p mimics + H/R, H9c2 cells transfected with miR-103a-3p mimic and then H/R; miR-103a-3p inhibitor, H9c2 cells transfected with miRNA inhibitor; inhibitor-Control, H9c2 cells transfected with miRNA inhibitor control. All data are expressed as the mean \pm standard deviation. ${ }^{*} \mathrm{P}<0.05,{ }^{* *} \mathrm{P}<0.01$ and ${ }^{* * *} \mathrm{P}<0.001$, vs. NC; ${ }^{\# \# \#} \mathrm{P}<0.001$, vs. H/R. miR, microRNA; NC, negative control; H/R, hypoxia/reoxygenation; Bcl-2, B-cell lymphoma 2; Bax, Bcl-2-associated X protein.

addition, the leakage of LDH in the miR-103a-3p mimics H/R group was significantly lower compared with that noted in the H/R group (Fig. 1C).

The detection of the expression levels of apoptotic proteins Bax, cleaved caspase- 3 and cleaved caspase- 9 by western blotting indicated that their levels were significantly upregulated in the $\mathrm{H} / \mathrm{R}$ and the miR-103a-3p inhibitor groups compared with those noted in the $\mathrm{NC}$ and inhibitor-con groups. In contrast to the apoptotic proteins, the anti-apoptotic protein $\mathrm{Bcl}-2$ was downregulated in the aforementioned groups, whereas the trend in the miR-103a-3p mimics $H / R$ group was the opposite to that noted in the H/R group (Fig. 2A and B). 
NC

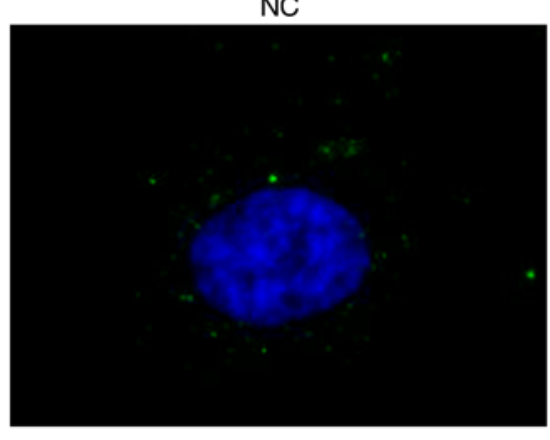

miR-103a-3p inhibitor

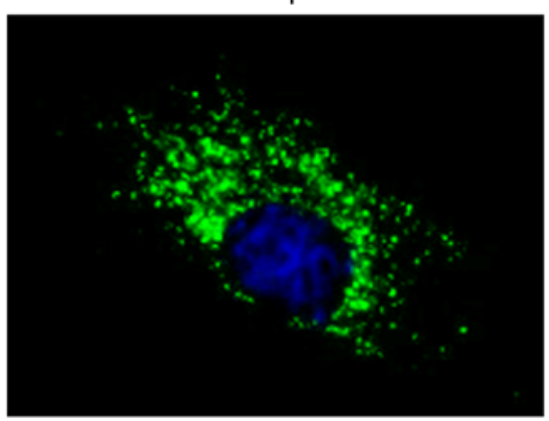

$H / R$

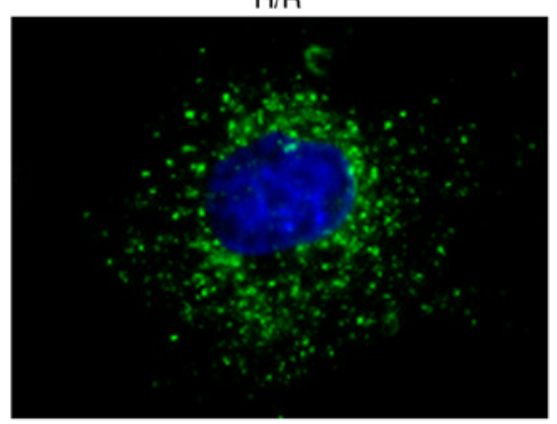

Mimic-control

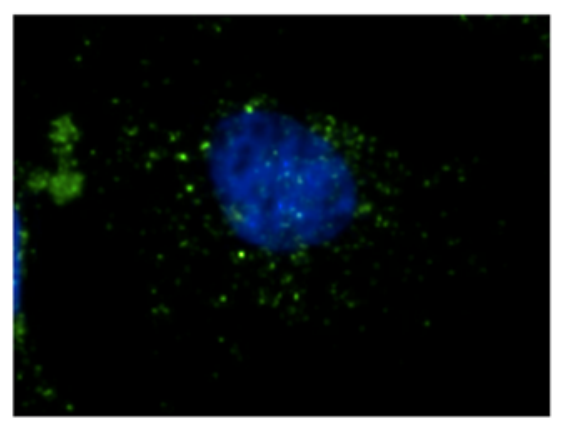

Inhibitor-control

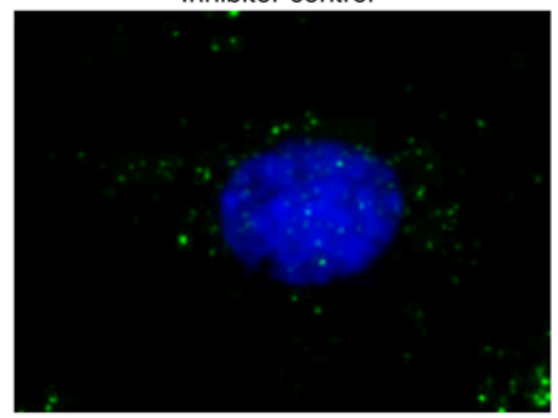

miR-103a-3p mimic $+H / R$

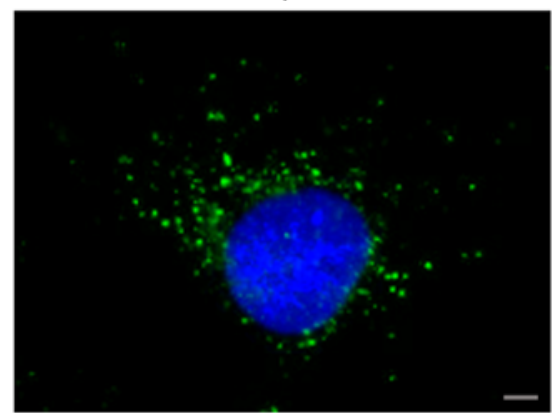

Figure 3. Induction of autophagy is associated with the expression of miR-103a-3p. Immunofluorescence of LC3 was detected in $\mathrm{H} 9 \mathrm{c} 2$ cells (scale bar, $10 \mu \mathrm{m}$ ). NC, untreated H9c2 cells; H/R, H9c2 cells under H/R; mimic-Control, H9c2 cells transfected with miRNA mimic control; miR-103a-3p mimics + H/R, H9c2 cells transfected with miR-103a-3p mimic and then H/R; miR-103a-3p inhibitor, H9c2 cells transfected with miRNA inhibitor; inhibitor-Control, H9c2 cells transfected with miRNA inhibitor control. miR, microRNA; NC, negative control; H/R, hypoxia/reoxygenation.

Induction of autophagy in H9c2 cardiomyocytes. The immunofluorescence staining indicated that LC3 was increased in the $\mathrm{H} / \mathrm{R}$ and the miR-103a-3p inhibitor groups. The expression levels of LC3II in the miR-103a-3p mimics H/R group were lower than those in the cells cultured under $H / R$ conditions (Fig. 3). The protein expression levels of Beclin-1 and Atg5, which are associated with the induction of autophagy, were also detected by western blotting. The levels of these two proteins were significantly increased in the $H / R$ and the miR-103a-3p inhibitor groups compared with those in the $\mathrm{NC}$ and inhibitor-con groups, whereas their levels were significantly decreased in the miR-103a-3p mimics H/R group compared with those in the H/R group (Fig. 4A and B). Furthermore, miR-103a-3p was observed to regulate the mRNA expression level of Atg5 (Fig. 4C). These results indicated that a reduction in the expression levels of miR-103a-3p promoted the induction of autophagy.

miR-103-3p regulates the induction of autophagy and apoptosis via Atg5. The present study further examined the association between Atg5 and miR-103a-3p. The luciferase reporter assays indicated that Atg5 was a direct and negative target of miR-103a-3p (Fig. 5A and B). Atg5-siRNA was used to efficiently knock down the expression of Atg5 in H9c2 cells (Fig. 5C).

To investigate the effect of Atg5 on H9c2 cardiomyocytes, the Atg5-siRNA H/R group of cells (H9c2 Atg5-siRNA cultured under $\mathrm{H} / \mathrm{R}$ condition) was used for further investigation. The cell viability of the Atg5-siRNA H/R group was higher than that of the H/R group, which was significantly decreased compared with that of the NC group (Fig. 6A). LDH leakage was significantly increased in the H/R group compared with that in the NC group, whereas LDH leakage in the Atg5-siRNA H/R group was significantly decreased (Fig. 6B). The expression levels of apoptotic proteins in the $\mathrm{NC}$ and siRNA-con groups did not differ significantly. The protein expression levels of Beclin-1, Bax, cleaved caspase 3 and cleaved caspase 9 were significantly upregulated and the levels of Bcl-2 were significantly downregulated in the H/R group compared with those in the NC group (Fig. 7). However, these proteins exhibited an opposite pattern of expression in the Atg5-siRNA H/R group compared with that of the H/R group (Fig. 7). The protein expression of LC3II in the H/R group was increased compared with that in the $\mathrm{NC}$ group, although the expression in the in the Atg5-siRNA H/R group was lower than that in the H/R group (Fig. 8). These results indicated that $\operatorname{Atg} 5$ is a potential target for miR-103a-3p.

\section{Discussion}

Recently, miRNAs have become a major focus of investigation with regard to the development of cardiovascular disease. In the present study, it was demonstrated that cardiomyocytes cultured under $\mathrm{H} / \mathrm{R}$ conditions were protected from the induction of apoptosis and excessive autophagy by miR-103a-3p. Furthermore, it was demonstrated that miR-103a-3p directly targets Atg5 which mediates the effects of miR-103a-3p in cardiomyocytes.

The induction of cardiomyocyte apoptosis is a rare event in the healthy myocardium and is the predominant form of cell death in the infarcted myocardium, which is often caused by ischemia $(31,32)$. It has been shown that miRNAs are associated with the induction of cardiomyocyte apoptosis following ischemic injury (33). As apoptosis is essential for cardiac 

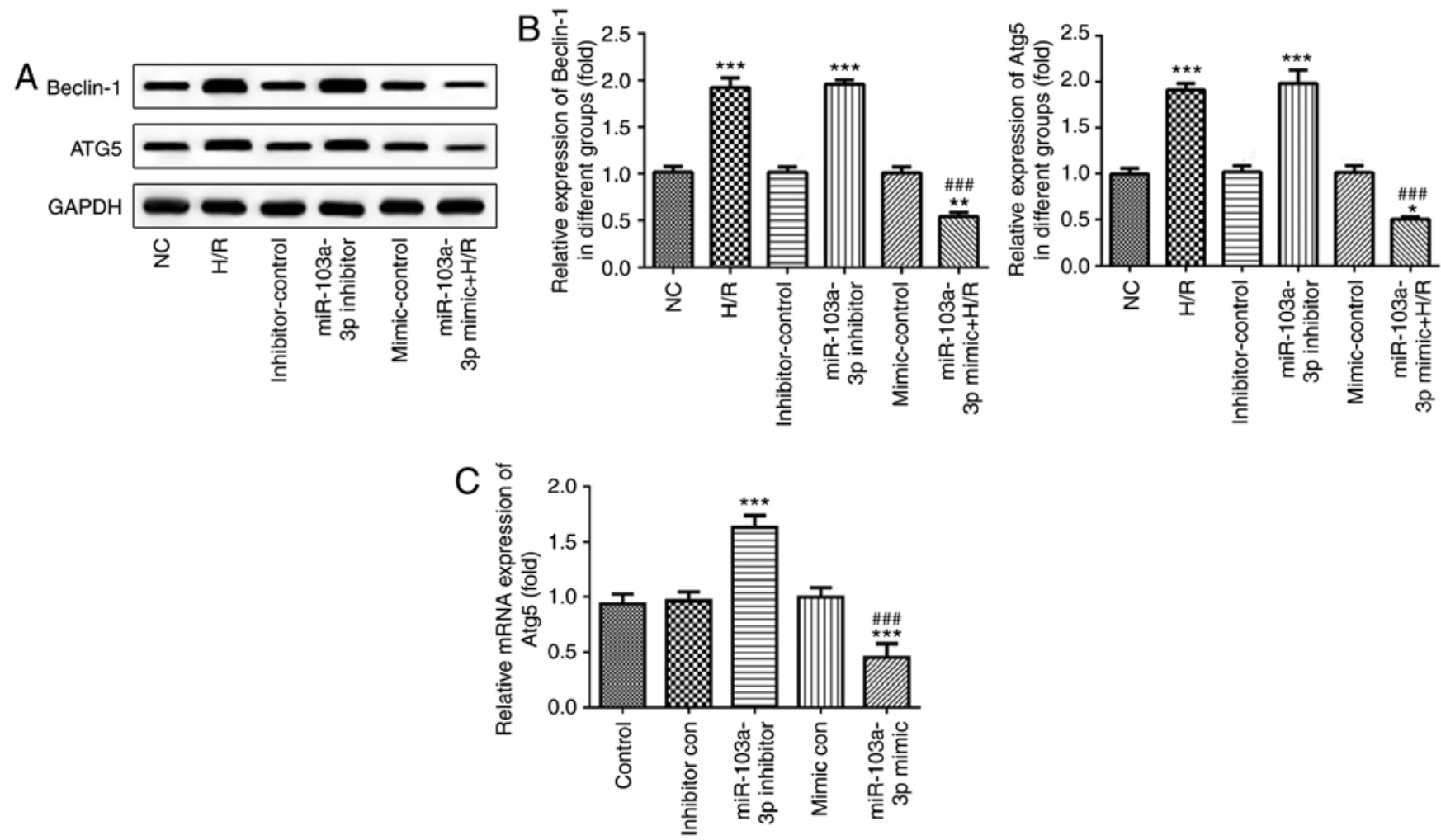

Figure 4. miR-103a-3p regulates the expression of autophagic proteins. Expression levels of Beclin-1 and Atg5 were (A) detected by western blotting and (B) results were quantified. (C) Expression levels of Atg 5 were examined by reverse transcription-quantitative polymerase chain reaction analysis. NC, untreated H9c2 cells; H/R, H9c2 cells under H/R; mimic-Control, H9c2 cells transfected with miRNA mimic control; miR-103a-3p mimic, H9c2 cells transfected with miR-103a-3p mimic; miR-103a-3p mimics + H/R, H9c2 cells transfected with miR-103a-3p mimic and then H/R; miR-103a-3p inhibitor, H9c2 cells transfected with miRNA inhibitor; inhibitor-Control, H9c2 cells transfected with miRNA inhibitor control. All data are expressed as the mean \pm standard deviation. ${ }^{*} \mathrm{P}<0.05,{ }^{* *} \mathrm{P}<0.01$ and ${ }^{* * *} \mathrm{P}<0.001$, vs. NC; ${ }^{\# \#} \mathrm{P}<0.001$, vs. H/R. miR, microRNA; NC, negative control; H/R, hypoxia/reoxygenation; Atg 5, autophagy-related 5 .

\section{A Atg5 3'UTR-MUT CCAGAAACACUUCGCAUCAAGGAA \\ miR-103a-3p AGUAUCGGGACAUGUUACGACGA \\ Atg5 3'UTR-WT CCAGAAACACUUCGCUGCUGCAA}
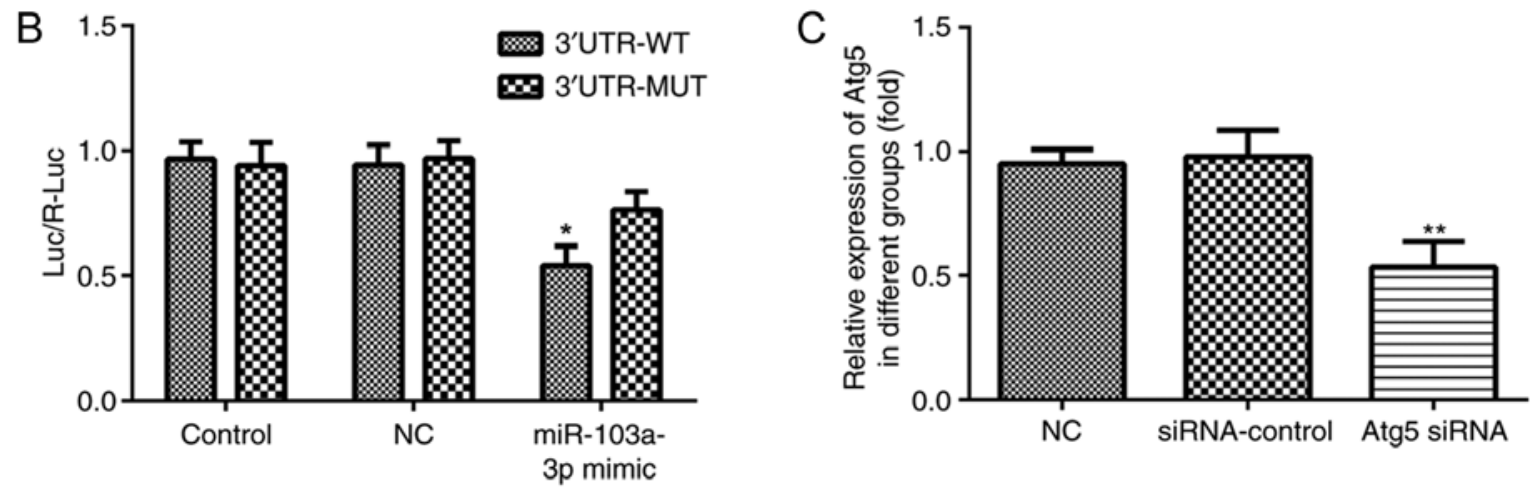

Figure 5. Atg5 is a potential target for miR-103a-3p. (A) Luciferase reporter assays were used to evaluate the interaction between miR-103a-3p and Atg5. (B) Quantification of results. Control, untreated cells; NC, cells co-transfected with miRNA control and 3'UTR WT or MUT; miR-103a-3p mimics, cells co-transfected with miR-103a-3p mimics and 3'UTR WT or MUT. (C) Relative mRNA expression levels of Atg5 were determined to detect the transfection efficiency. All data are expressed as the mean \pm standard deviation. " $\mathrm{P}<0.01$, vs. control; ${ }^{* *} \mathrm{P}<0.01$, vs. NC. miR, microRNA; NC, negative control; 3 'UTR, 3' untranslated region; WT, wild-type; MUT, mutant; siRNA, small interfering RNA; Atg5, autophagy-related 5; luc, luciferase.

injury (34), the present study detected the levels of apoptosis in cardiomyocytes and verified that apoptosis was significantly increased in $\mathrm{H} 9 \mathrm{c} 2$ cells cultured under H/R conditions. A previous study showed that miR-103a-3p was associated with the induction of apoptosis in human glioma stem cells (35). Another previous study showed that miR-103a-3p was 
A

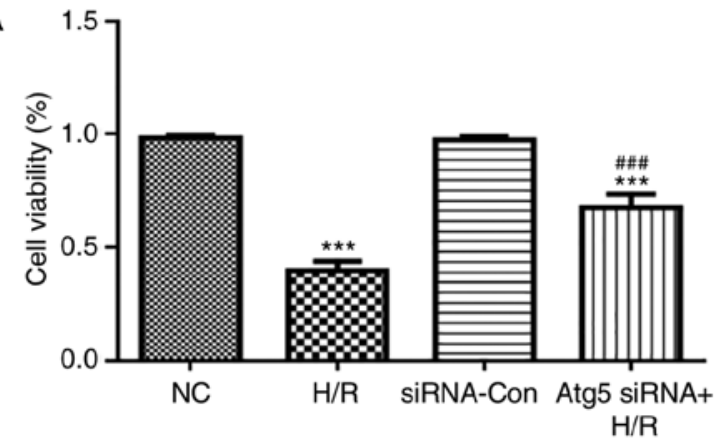

B

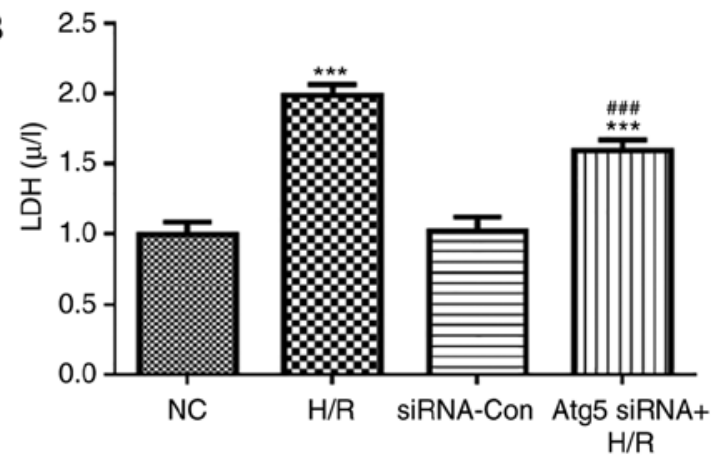

Figure 6. Cell viability is associated with Atg5. (A) MTT assay was used to detect cell viability in the four groups. (B) LDH leakage was evaluated to detect cell injury in the four groups. NC, normal H9c2 control cells; H/R, H9c2 cells under H/R; siRNA-Con, H9c2 cells transfected with control siRNA; Atg5-siRNA + H/R, H9c2 cells transfected with Atg5-siRNA and then H/R. All data are expressed as the mean \pm standard deviation. ${ }^{* * * *} \mathrm{P}<0.001$, vs. NC; ${ }^{\# \# \# ~} \mathrm{P}<0.001$, vs. $\mathrm{H} / \mathrm{R}$. miR, microRNA; H/R, hypoxia/reoxygenation; NC, negative control; siRNA, small interfering RNA; Atg5, autophagy-related 5; LDH, lactate dehydrogenase.
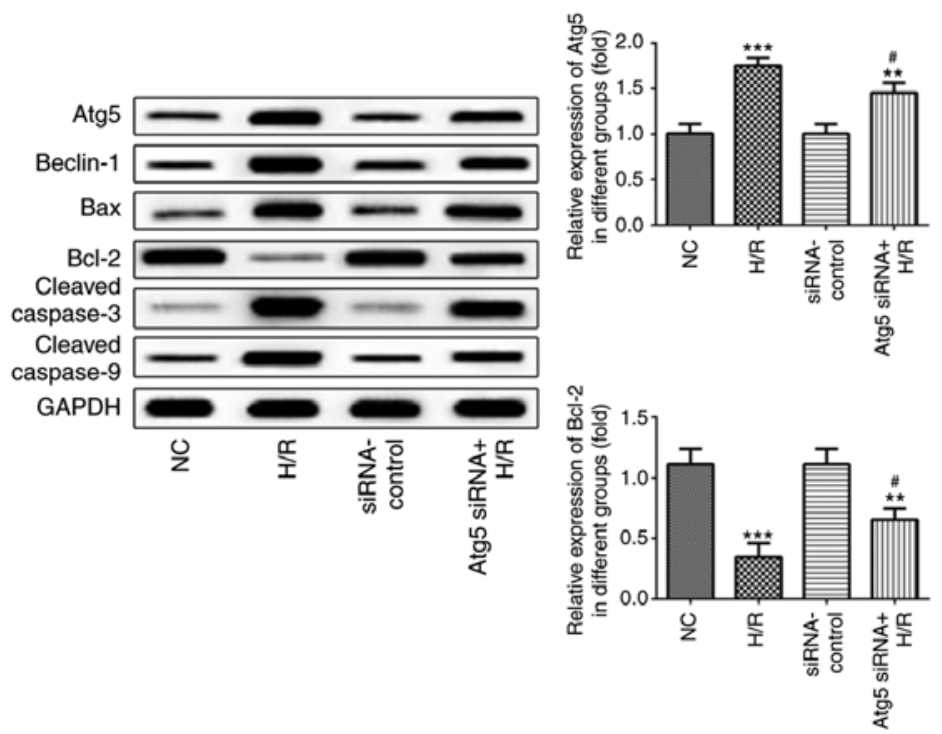
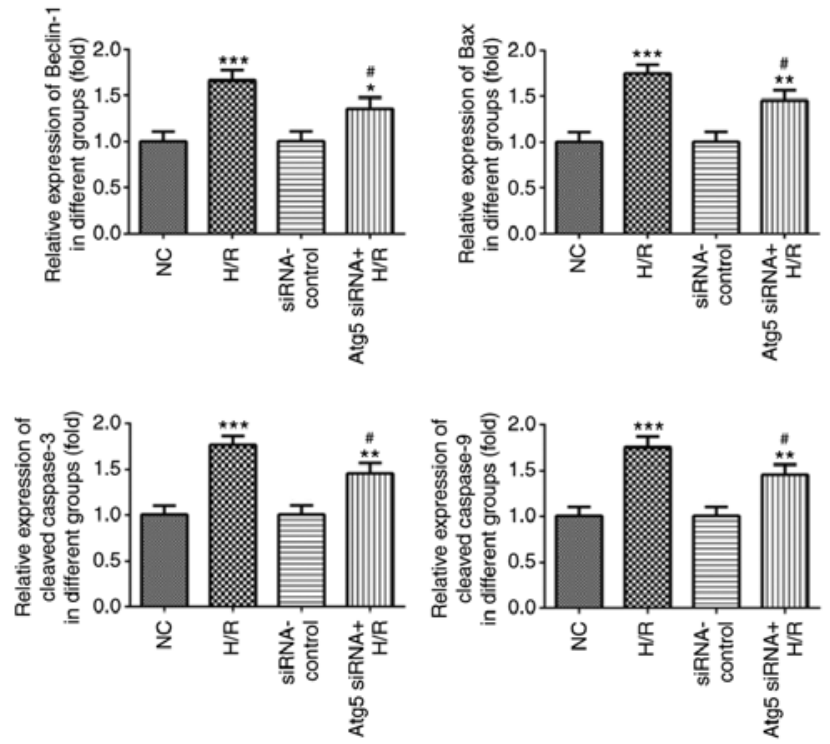

Figure 7. Expression levels of apoptotic proteins and autophagic proteins and their quantitative evaluation in cells cultured under $\mathrm{H} / \mathrm{R}$ conditions or in cells transfected with Atg-siRNA. All data are expressed as the mean \pm standard deviation. ${ }^{*} \mathrm{P}<0.05,{ }^{* *} \mathrm{P}<0.01$ and ${ }^{* * * *} \mathrm{P}<0.001$, vs. NC; ${ }^{\text {" }} \mathrm{P}<0.05$, vs. $\mathrm{H} / \mathrm{R}$. siRNA-control and NC did not differ significantly. miR, microRNA; H/R, hypoxia/reoxygenation; NC, negative control; siRNA, small interfering RNA; Atg5, autophagy-related 5; Bcl-2, B-cell lymphoma 2; Bax, Bcl-2-associated X protein.

also upregulated in ischemic dilated cardiomyopathy (36). Furthermore, the levels of miR-103a-3p were significantly decreased in $\mathrm{H} 9 \mathrm{c} 2$ cells cultured under $\mathrm{H} / \mathrm{R}$ conditions, which mimic I/R conditions. Therefore, miR-103a-3p may be involved in $I / R$ via the regulation of apoptosis. Further analysis confirmed these conclusions using miR-103a-3p inhibition and overexpression cell models. The results indicated that the expression of miR-103a-3p was inhibited following the induction of apoptosis by H/R injury, whereas the overexpression of miR-103a-3p inhibited this process. This indicated that the upregulation of miR-103a-3p inhibited the induction of apoptosis under $\mathrm{H} / \mathrm{R}$ conditions. In addition, cell apoptosis is a process of cell death and can be promoted by the release of cytochrome $c$, cleaved caspase- 3 and cleaved caspase- 9 , which are essential in the formation of apoptotic bodies $(37,38)$. Bcl-2 prevents the permeabilization of mitochondria to inhibit $\mathrm{Ca}^{2+}$ overload and consequently the activity of cleaved caspases, whereas Bax exerts the opposite effects (39). A previous study showed that the Bcl-2 family proteins are important in myocardial I/R injury (40). The results of the present study are in accordance with previous investigations and demonstrated the downregulation of Bcl-2 and the upregulation of Bax, cleaved caspase- 3 and cleaved caspase- 9 proteins. The interaction between Bcl-2, Bax, cleaved caspase-3 and cleaved caspase- 9 proteins and $\mathrm{I} / \mathrm{R}$ injury require further investigation.

Autophagy or 'self-devouring' is the natural, regulated, destructive mechanism of the cell that removes unnecessary or dysfunctional components (41). It is a constitutive housekeeping process involved in the progression of cardiovascular disease $(42,43)$. A number of studies have revealed the role of miRNAs in regulating autophagy in cardiomyocytes $(44,45)$. In the present study, the LC3 protein was expressed at high levels and assembled in the cytoplasm of $\mathrm{H} 9 \mathrm{c} 2$ cells under $\mathrm{H} / \mathrm{R}$ conditions, or in $\mathrm{H} 9 \mathrm{c} 2$ cells transfected with miR-103a-3p inhibitor, compared with control cells. These findings revealed that the downregulation of miR-103a-3p promoted autophagy. The induction of cell apoptosis was accompanied with autophagy, as the two processes were promoted in the cell line 
NC

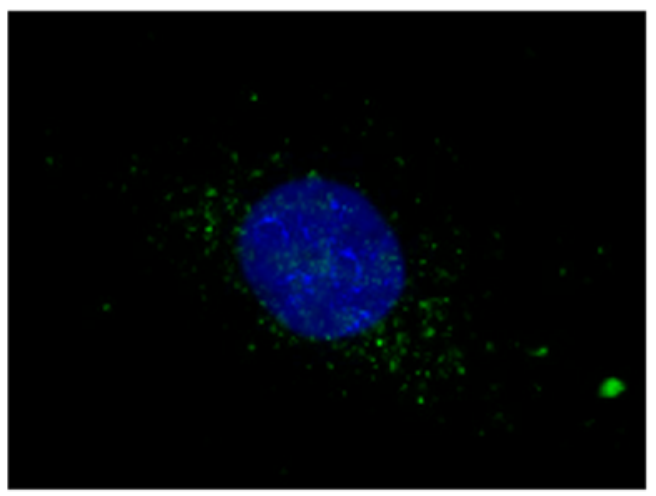

siRNA-contro

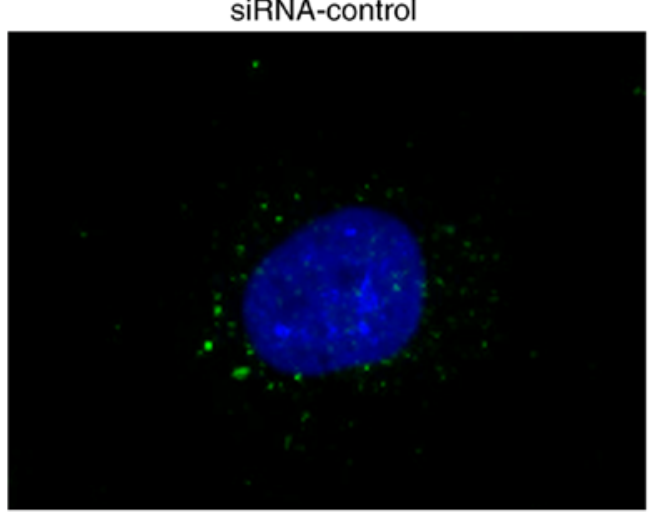

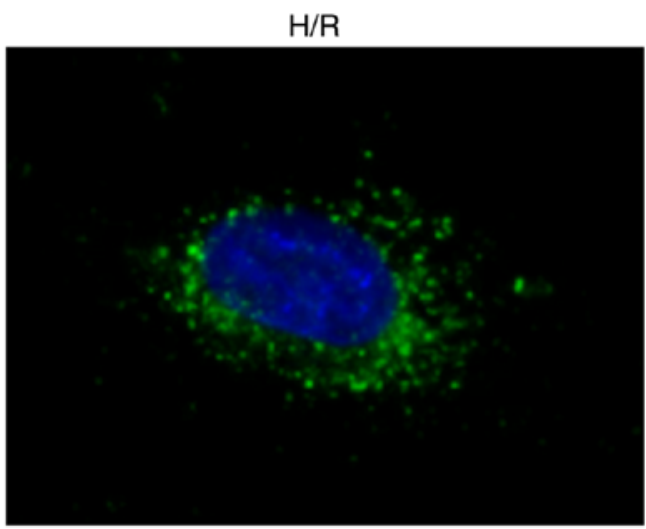

$\operatorname{Atg} 5 \mathrm{siRNA}+\mathrm{H} / \mathrm{R}$

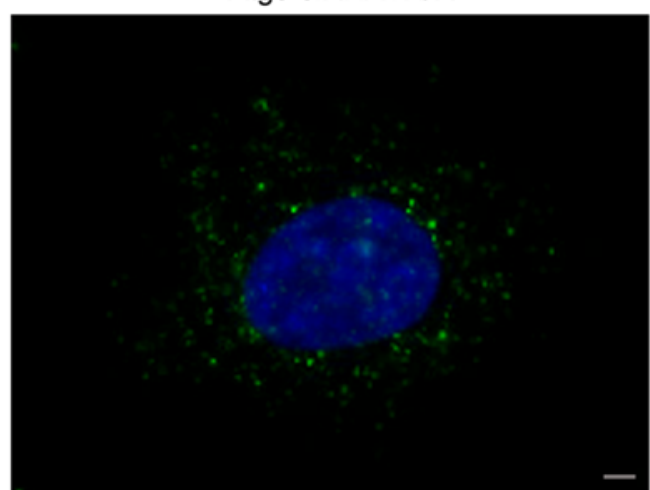

Figure 8. Induction of autophagy is associated with the expression of Atg5. Immunofluorescence of LC3 was detected in the four H9c2 cell groups (scale bar, $10 \mu \mathrm{m})$. NC, normal H9c2 control cells; H/R, H9c2 cells under H/R; siRNA-Con, H9c2 cells transfected with control siRNA; Atg5-siRNA + H/R, H9c2 cells transfected with Atg5-siRNA and then H/R. miR, microRNA; H/R, hypoxia/reoxygenation; NC, negative control; siRNA, small interfering RNA; Atg5, autophagy-related 5

models used. Therefore, the downregulation of miR-103a-3p injures cardiomyocytes by inducing autophagy.

Autophagy and apoptosis are two types of programmed cell death (46). The induction of autophagy depends on the expression of Atg proteins; two of the most important ubiquitination pathways are the Atg8(LC3)-PE and Atg12-Atg5-Atg16L pathways, which are involved in autophagosome formation. A previous study showed that the same inducible factors can induce autophagy or apoptosis in different cells, as demonstrated by the expression of Beclin-1, Atg4, Atg5 and Bcl-2 (47). Atg5 is attached to the autophagic vacuole membrane in order to facilitate LC3 binding (48). Evidence suggests that autophagy induces cell death under certain conditions. Additionally, a previous study indicated that Atg5 promoted apoptotic cell death via the activation of caspase-8 (49). In the present study, the expression of Atg5 was upregulated by the inhibition of miR-103a-3p. Concomitantly, the levels of miR-103a-3p were not altered when the expression of Atg 5 was inhibited prior to the induction of $\mathrm{H} / \mathrm{R}$, indicating that the regulation of Atg5 by miR-103a-3p was unidirectional (Fig. S1). Furthermore, Atg5 was downregulated in the miR-103a-3p mimics group compared with that in the H/R group at the mRNA and protein levels, which indicates that miR-103a-3p regulated the expression of Atg5 through gene expression. miRNAs usually bind to a complementary sequence in the $3^{\prime} \mathrm{UTR}$ of specific target genes in order to regulate their cellular functions (50). The luciferase reporter assay indicated that miR-103a-3p directly targeted the 3'UTR of the Atg5 gene. Concomitantly, the mRNA expression levels of Atg5 were significantly decreased following the overexpression of miR-103a-3p. Therefore, miR-103a-3p directly targeted Atg 5 to downregulate its levels. Of note, the expression levels of the apoptotic protein was not significantly decreased following the inhibition of Atg5 under H/R compared with that in the H/R group. A previous report also indicated that Atg5 promoted autophagy for cell death (51). Further investigation of the induction of apoptosis by the downregulation of miR-103a-3p, and whether this effect is mediated by Atg5, is required. In was also found that LC3 was decreased in $\mathrm{H} 9 \mathrm{c} 2$ cells transfected with Atg 5 siRNA under H/R conditions compared with that in the $\mathrm{H} 9 \mathrm{c} 2 \mathrm{H} / \mathrm{R}$ group, which indicates that autophagy may be mediated by Atg5. In the present study, Atg5 knockdown also inhibited cell death induced by H/R.

It has been shown that Bcl-2 is a well-characterized apoptotic protein, which is considered an important binding partner of Beclin-1 required to regulate autophagy (52). Disruption of the Bcl-2-Beclin interaction induces autophagy (27). In the present study, autophagy was induced in $\mathrm{H} 9 \mathrm{c} 2$ cells under $\mathrm{H} / \mathrm{R}$ conditions and in H9c2 cells transfected with the miR-103a-3p inhibitor. These two types of cell line models exhibited high protein expression levels of Beclin-1. Concomitantly, the expression levels of Bcl-2 were significantly decreased. This indicated that Beclin-1 is involved in the regulation of autophagy in cardiomyocytes.

In conclusion, the data obtained in the present study demonstrated that miR-103a-3p has a protective role in myocardial I/R injury. The mechanisms involve anti-apoptotic and 
anti-autophagic effects through increasing the expression of Atg5. In addition, miR-103a-3p also promoted the expression of Belin-1, which is associated with autophagosome formation. Collectively, these observations provide novel insight into the treatment of myocardial ischemia.

\section{Acknowledgements}

Not applicable.

\section{Funding}

Funding was provided by the Key Special Project of Pudong New Area Health System (grant no. PWZzk2017-23).

\section{Availability of data and materials}

The datasets used and/or analyzed during the present study are available from the corresponding author on reasonable request.

\section{Authors' contributions}

$\mathrm{CZ}$ contributed to this article, including the study design, data analysis, data interpretation and drafting of the manuscript. JL and HW collected and analyzed the data. HW and YQ provided suggestions for study design and data analysis. YK and $\mathrm{ZG}$ provided key suggestions on study design and edited the language of the manuscript. All authors have read and approved the final manuscript.

\section{Ethics approval and consent to participate}

Not applicable.

\section{Patient consent for publication}

Not applicable.

\section{Competing interests}

The authors declare that they have no competing interests.

\section{References}

1. Benjamin EJ, Blaha MJ, Chiuve SE, Cushman M, Das SR, Deo R, de Ferranti SD, Floyd J, Fornage M, Gillespie C, et al Heart disease and stroke statistics-2017 update: A report from the american heart association. Circulation 135: e146-e603, 2017

2. Bochaton T and Ovize M: Circadian rhythm and ischaemia-reperfusion injury. Lancet 391: 8-9, 2018.

3. Montaigne D, Marechal X, Modine T, Coisne A, Mouton S, Fayad G, Ninni S, Klein C, Ortmans S, Seunes C, et al: Daytime variation of perioperative myocardial injury in cardiac surgery and its prevention by Rev-Erb $\alpha$ antagonism: A single-centre propensity-matched cohort study and a randomised study. Lancet 391: 59-69, 2018.

4. Pattingre S, Tassa A, Qu X, Garuti R, Liang XH, Mizushima N, Packer M, Schneider MD and Levine B: Bcl-2 antiapoptotic proteins inhibit Beclin 1-dependent autophagy. Cell 122: 927-939, 2005

5. Ghavami S, Gupta S, Ambrose E, Hnatowich M, Freed DH and Dixon IM: Autophagy and heart disease: Implications for cardiac ischemia-reperfusion damage. Curr Mol Med 14: 616-629, 2014.

6. Nishida K, Kyoi S, Yamaguchi O, Sadoshima J and Otsu K: The role of autophagy in the heart. Cell Death Differ 16: 31-38, 2009
7. Matsui Y, Takagi H, Qu X, Abdellatif M, Sakoda H, Asano T, Levine B and Sadoshima J: Distinct roles of autophagy in the heart during ischemia and reperfusion: Roles of AMP-activated protein kinase and Beclin 1 in mediating autophagy. Circ Res 100: 914-922, 2007

8. Zhu H, Tannous P, Johnstone JL, Kong Y, Shelton JM, Richardson JA, Le V, Levine B, Rothermel BA and Hill JA: Cardiac autophagy is a maladaptive response to hemodynamic stress. J Clin Invest 117: 1782-1793, 2007.

9. Lavandero S, Troncoso R, Rothermel BA, Martinet W, Sadoshima J and Hill JA: Cardiovascular autophagy: Concepts, controversies, and perspectives. Autophagy 9: 1455-1466, 2013.

10. Moss EG: MicroRNAs: Hidden in the genome. Curr Biol 12: R138-R140, 2002.

11. Ambros V: microRNAs: Tiny regulators with great potential. Cell 107: 823-826, 2001.

12. Salem M, O'Brien JA, Bernaudo S, Shawer H, Ye G, Brkić J, Amleh A, Vanderhyden BC, Refky B, Yang BB, et al: miRNA-590-3p promotes ovarian cancer growth and metastasis via a novel FOXA2-versican pathway. Cancer Res 78: 4175-4190, 2018.

13. Sun F, Yu M, Yu J, Liu Z, Zhou X, Liu Y, Ge X, Gao H, Li M, Jiang $\mathrm{X}$, et al: miR-338-3p functions as a tumor suppressor in gastric cancer by targeting PTP1B. Cell Death Dis 9: 522, 2018.

14. Zitzer NC, Snyder K, Meng X, Taylor PA,Efebera YA, Devine SM, Blazar BR, Garzon R and Ranganathan P: MicroRNA-155 modulates acute graft-versus-host disease by impacting $\mathrm{T}$ cell expansion, migration, and effector function. J Immunol 200: 4170-4179, 2018.

15. Janaszak-Jasiecka A, Siekierzycka A, Bartoszewska S, Serocki M Dobrucki LW, Collawn JF, Kalinowski L and Bartoszewski R: eNOS expression and NO release during hypoxia is inhibited by miR-200b in human endothelial cells. Angiogenesis 21: 711-724, 2018.

16. Voshall A, Kim EJ, Ma X, Yamasaki T, Moriyama EN and Cerutti H: miRNAs in the alga Chlamydomonas reinhardtii are not phylogenetically conserved and play a limited role in responses to nutrient deprivation. Sci Rep 7: 5462, 2017.

17. Wei S, Xue J, Sun B, Zou Z, Chen C, Liu Q and Zhang A: miR-145 via targeting ERCC2 is involved in arsenite-induced DNA damage in human hepatic cells. Toxicol Lett 295: 220-228, 2018.

18. Wang X, Ha T, Hu Y, Lu C, Liu L, Zhang X, Kao R, Kalbfleisch J, Williams D and Li C: MicroRNA-214 protects against hypoxia/reoxygenation induced cell damage and myocardial ischemia/reperfusion injury via suppression of PTEN and Bim1 expression. Oncotarget 7: 86926-86936, 2016.

19. Bartman CM, Oyama Y, Brodsky K, Khailova L, Walker L, Koeppen $\mathrm{M}$ and Eckle $\mathrm{T}$ : Intense light-elicited upregulation of miR-21 facilitates glycolysis and cardioprotection through Per2-dependent mechanisms. PLoS One 12: e0176243, 2017.

20. Weber DG, Casjens S, Johnen G, Bryk O, Raiko I, Pesch B, Kollmeier J, Bauer TT and Brüning T: Combination of MiR-103a-3p and mesothelin improves the biomarker performance of malignant mesothelioma diagnosis. PLoS One 9: e114483, 2014.

21. Zhong Z, Lv M and Chen J: Screening differential circular RNA expression profiles reveals the regulatory role of circTCF25-miR-103a-3p/miR-107-CDK6 pathway in bladder carcinoma. Sci Rep 6: 30919, 2016.

22. Hu X, Miao J, Zhang M, Wang X, Wang Z, Han J, Tong D and Huang C: miRNA-103a-3p promotes human gastric cancer cell proliferation by targeting and suppressing ATF7 in vitro. Mol Cells 41: 390-400, 2018

23. Kang S, Shin KD, Kim JH and Chung T: Autophagy-related (ATG) 11, ATG9 and the phosphatidylinositol 3-kinase control ATG2-mediated formation of autophagosomes in Arabidopsis. Plant Cell Rep 37: 653-664, 2018.

24. Mizushima N, Noda T, Yoshimori T, Tanaka Y, Ishii T, George MD, Klionsky DJ, Ohsumi M and Ohsumi Y: A protein conjugation system essential for autophagy. Nature 395: 395-398, 1998.

25. Ravikumar B,Imarisio S, Sarkar S, O'Kane CJ and Rubinsztein DC: Rab5 modulates aggregation and toxicity of mutant huntingtin through macroautophagy in cell and fly models of Huntington disease. J Cell Sci 121: 1649-1660, 2008.

26. Liang XH, Jackson S, Seaman M, Brown K, Kempkes B, Hibshoosh H and Levine B: Induction of autophagy and inhibition of tumorigenesis by beclin 1. Nature 402: 672-676, 1999. 
27. Sun T, Li X, Zhang P, Chen WD, Zhang HL, Li DD, Deng R, Qian XJ, Jiao L, Ji J, et al: Acetylation of Beclin 1 inhibits autophagosome maturation and promotes tumour growth. Nat Commun 6: 7215, 2015

28. Nishida Y, Arakawa S, Fujitani K, Yamaguchi H, Mizuta T Kanaseki T, Komatsu M, Otsu K, Tsujimoto Y and Shimizu S: Discovery of Atg5/Atg7-independent alternative macroautophagy. Nature 461: 654-658, 2009.

29. Kabeya Y, Mizushima N, Ueno T, Yamamoto A, Kirisako T, Noda T, Kominami E, Ohsumi Y and Yoshimori T: LC3, a mammalian homologue of yeast Apg8p, is localized in autophagosome membranes after processing. EMBO J 19: 5720-5728, 2000.

30. Livak KJ and Schmittgen TD: Analysis of relative gene expression data using real-time quantitative PCR and the 2(-Delta Delta C(T)) method. Methods 25: 402-408, 2001.

31. Bainey KR and Armstrong PW: Clinical perspectives on reperfusion injury in acute myocardial infarction. Am Heart J 167: 637-645, 2014

32. Tian ZQ, Jiang H and Lu ZB: MiR-320 regulates cardiomyocyte apoptosis induced by ischemia-reperfusion injury by targeting AKIP1. Cell Mol Biol Lett 23: 41, 2018.

33. Di Y, Lei Y, Yu F, Changfeng F, Song W and Xuming M: MicroRNAs expression and function in cerebral ischemia reperfusion injury. J Mol Neurosci 53: 242-250, 2014.

34. Liu X, Deng Y, Xu Y, Jin W and Li H: MicroRNA-223 protects neonatal rat cardiomyocytes and $\mathrm{H} 9 \mathrm{c} 2$ cells from hypoxia-induced apoptosis and excessive autophagy via the Akt/mTOR pathway by targeting PARP-1. J Mol Cell Cardiol 118: 133-146, 2018.

35. Yu M, Xue Y, Zheng J, Liu X, Yu H, Liu L, Li Z and Liu Y: Linc00152 promotes malignant progression of glioma stem cells by regulating miR-103a-3p/FEZF1/CDC25A pathway. Mol Cancer 16: 110, 2017.

36. Onrat ST, Onrat E, Ercan Onay E, Yalim Z and Avşar A: The genetic determination of the differentiation between ischemic dilated cardiomyopathy and idiopathic dilated cardiomyopathy. Genet Test Mol Biomarkers 22: 644-651, 2018.

37. Chen L, Li G, Peng F, Jie X, Dongye G, Cai K, Feng R, Li B, Zeng $\mathrm{Q}$, Lun $\mathrm{K}$, et al: The induction of autophagy against mitochondria-mediated apoptosis in lung cancer cells by a ruthenium (II) imidazole complex. Oncotarget 7: 80716-80734, 2016.

38. Zhang Q, Xiang J, Wang X, Liu H, Hu B, Feng M and Fu Q: Beta(2)-adrenoceptor agonist clenbuterol reduces infarct size and myocardial apoptosis after myocardial ischaemia/reperfusion in anaesthetized rats. Br J Pharmacol 160: 1561-1572, 2010.

39. Nishihara M, Miura T, Miki T, Tanno M, Yano T, Naitoh K, Ohori K, Hotta H, Terashima Y and Shimamoto K: Modulation of the mitochondrial permeability transition pore complex in GSK-3beta-mediated myocardial protection. J Mol Cell Cardiol 43: 564-570, 2007.

40. Mazel S, Burtrum D and Petrie HT: Regulation of cell division cycle progression by bcl-2 expression: A potential mechanism for inhibition of programmed cell death. J Exp Med 183: 2219-2226, 1996.
41. Carlsson SR and Simonsen A: Membrane dynamics in autophagosome biogenesis. J Cell Sci 128: 193-205, 2015.

42. Chen C, Chen W, Li Y, Dong Y, Teng X, Nong Z, Pan X, Lv L, Gao Y and Wu G: Hyperbaric oxygen protects against myocardial reperfusion injury via the inhibition of inflammation and the modulation of autophagy. Oncotarget 8: 111522-111534, 2017.

43. Wu Y, Fan W, Huang D and Sun X: Possible intermediary role of autophagy in serum albumin decrease-associated cardiovascular events among patients with coronary heart disease. Int J Cardiol 250: 64, 2018.

44. Chen L, Wang FY, Zeng ZY, Cui L, Shen J, Song XW, Li P, Zhao XX and Qin YW: MicroRNA-199a acts as a potential suppressor of cardiomyocyte autophagy through targeting Hspa5. Oncotarget 8: 63825-63834, 2017.

45. Huang Z, Wu S, Kong F, Cai X, Ye B, Shan P and Huang W: MicroRNA-21 protects against cardiac hypoxia/reoxygenation injury by inhibiting excessive autophagy in $\mathrm{H} 9 \mathrm{c} 2$ cells via the Akt/mTOR pathway. J Cell Mol Med 21: 467-474, 2017

46. Shang YY, Yao M, Zhou ZW, Jian-Cui, Li-Xia, Hu RY, Yu YY, Qiong-Gao, Biao-Yang, Liu YX, et al: Alisertib promotes apoptosis and autophagy in melanoma through p38 MAPK-mediated aurora a signaling. Oncotarget 8: 107076-107088, 2017.

47. Cheng Y and Yang JM: Autophagy and apoptosis: Rivals or mates? Chin J Cancer 32: 103-105, 2013.

48. Malhotra R, Warne JP, Salas E, Xu AW and Debnath J: Loss of Atg12, but not Atg5, in pro-opiomelanocortin neurons exacerbates diet-induced obesity. Autophagy 11: 145-154, 2015.

49. Young MM, Takahashi Y, Khan O, Park S, Hori T, Yun J, Sharma AK, Amin S, Hu CD, Zhang J, et al: Autophagosomal membrane serves as platform for intracellular death-inducing signaling complex (iDISC)-mediated caspase- 8 activation and apoptosis. J Biol Chem 287: 12455-12468, 2012.

50. Park JH and Shin C: MicroRNA-directed cleavage of targets: Mechanism and experimental approaches. BMB Rep 47: 417-423, 2014.

51. Arakawa S, Tsujioka M, Yoshida T, Tajima-Sakurai $H$, Nishida Y, Matsuoka Y, Yoshino I, Tsujimoto Y and Shimizu S: Role of Atg5-dependent cell death in the embryonic development of Bax/Bak double-knockout mice. Cell Death Differ 24: 1598-1608, 2017.

52. Luo S and Rubinsztein DC: Atg5 and Bcl-2 provide novel insights into the interplay between apoptosis and autophagy. Cell Death Differ 14: 1247-1250, 2007.

This work is licensed under a Creative Commons Attribution-NonCommercial-NoDerivatives 4.0 International (CC BY-NC-ND 4.0) License. 